\title{
Optimization of water resources for cropping pattern under sustainable conditions through fuzzy logic system
}

\author{
S. S. Valunjkar \\ Department of Civil Engineering, \\ Government College of Engineering, Aurangabad, India
}

\begin{abstract}
The optimization problem attempts to find a suitable combination, out of many feasible combinations of resources and their allocations, which maximizes a benefit or minimizes a cost subject to given constraints expressed through simple linear algebraic expression or equations. The Fuzzy Interface System (FIS) has many applications in water resources engineering. It has been used for planning the conjunctive use of surface water in canal command regions. The proposed FIS supports the cooperation between water administration and water users, and the cultivators in relation to revising cropping patterns. Fuzzy system modelling considers the fuzziness in the variables, which can be implemented in the field. The degree of satisfaction gives the reliability of the fuzzy modelling. In the earlier studies, many researches have included the fuzziness in a linguistic form and also included either in the inflow or in the demand. Hence, it is felt necessary to carry out study on development and application of fuzzy logic systems in context with the sustainable development. The model was used in command regions under the Pench irrigation project of Maharashtra State, India for determining optimal cropping activities during kharif, rabi, and hot weather seasons so as to maximize economic returns to the agricultural producers by making most efficient use of surface water resources at different reliable flow conditions.
\end{abstract}

Keywords: sustainable conditions, fuzzy interface systems. 


\section{Introduction}

The water resources scenario of India is dependent on the vagaries of monsoons and wide variation in spatial and temporal distribution of rainfall, resulting in drought-flood-drought syndrome. Nearly one third of the country is droughtprone while one eighth of the country is flood-prone. The explosive increase in population is adding pressure on water resources. Necessity has arisen now for a scientific approach to the problems so as to meet the future needs. The National Water Policy suggests that the water resources development projects should, as far as possible, be planned and developed as multi-purpose projects, with the drinking water supply as top priority, followed by irrigation, hydropower, flood control, recreation etc. The situation calls for an optimal utilization of the limited water resources through integrated operation at river basin level for the projects already developed and for integrated planning for the new projects so as to utilize the available water resources in most optimal manner.

The water resources scenario in Maharashtra State is drought-prone due to frequent failures of monsoon, and occasionally flood-prone due to excessive rainfall. The state enjoys the available surface water resources from the major projects viz. Koyna, Jayakwadi, Purna, Pench etc. but with the growing needs population there is a necessity to conserve these resources with application of system analysis techniques. Agriculture sector consumes around $80 \%$ of the available resources and this point to the fact that there is a scope for conservation of water in this area, if the proper management strategies are applied. The need of the hour is to apply modern methods to conserve the available water resources.

Fortnightly inflow data as recorded by the Irrigation Department, Government of Maharashtra, has slightly been modified for arithmetic discrepancies, to use in the simulation studies to assess the area which may be reliably irrigated. In the present study, these inflow values from 1914 to 1993 are used to develop the stochastic model for forecasting the inflows. The statistical properties of the data series are presented in the results and the reservoir release policies for the Pench river project are framed on inflows to the reservoir and the initial storage available at the beginning of the season. Even though the policy for reservoir releases is framed for a season/year, based on average inflows, its application is constrained by the average inflows taking place during the operational period. Optimization of reservoir releases at the planning stage becomes necessary in order to comply with the normal operational system constraints. The system formulation is based on mathematical modelling and its behaviour is assessed in terms of cost of the system or benefits generated by it, under the influence of restrictions as imposed on its working. The best system is the one for which the cost is minimum or the benefit is maximum such a system is called optimal system, which is used in decision making process. Fuzzy logic system supports the cooperation between water administration and water users. Fuzzy system modelling considers the fuzziness in the variables, which can be implemented in the field. The degree of satisfaction gives the reliability of the fuzzy modelling. In the earlier studies, many researches have included the fuzziness in a linguistic 
form and also included either in the inflow or in the demand. Hence, it is felt necessary to carry out detailed study on development and application fuzzy logic system in context with the sustainable development.

\section{Case study: Pench river project complex}

Pench river project complex comprises, hydro-electric and irrigation project on Pench river system. It is an Inter-state project between Maharashtra and Madhya Pradesh states of India. It envisages a storage dam, underground power house (with installed capacity $160 \mathrm{MW}$ ) and $8 \mathrm{~km}$ tailrace tunnel on downstream. The hydro-electric project at Totaladoh is designed at $90 \%$ dependable flow (or yield). The drainage area up to Pench hydro-electric project site is $4273 \mathrm{~km}^{2}$ out of which only $34 \mathrm{~km}^{2}$ is in Maharashtra state and rest lies in the state of Madhya Pradesh. Pench irrigation project comprises, a storage-cum-diversion dam located at Navegaon-Khairy (earlier name Kamptee-Khairy), $23 \mathrm{~km}$ downstream of Pench hydro-electric project. The drainage area between Pench hydro-electric and Pench irrigation project is $388 \mathrm{~km}^{2}$ which lies in Nagpur District of Maharashtra state. Two lined canals take off directly on left and right banks to irrigate an area of 104,476 hectares (Ha) in Nagpur and Bhandara districts of Maharastra state. This includes 10,000 hectares of irrigation from Ramsagar (Khindsi) tank. Presently the irrigation project is designed at $75 \%$ dependable yield. Besides irrigation, this projects also supplies water to Nagpur City, Ramtek town, thermal power stations at Koradi and Khaparkheda, and nearby industries. The length of left bank canal (LBC) is $32.85 \mathrm{~km}$ having carrying capacity of $90 \mathrm{~m}^{3} / \mathrm{s}$ at head, to irrigate an area of 73,900 $\mathrm{Ha}$ in Nagpur and Bhandara districts. The length of Right Bank canal (RBC) is $48.40 \mathrm{~km}$ and has a carrying capacity of $28 \mathrm{~m}^{3} / \mathrm{s}$ at head. It irrigates $30,576 \mathrm{Ha}$ in Nagpur district, in addition, to domestic and industrial water supply.

\subsection{Hydrology}

Generally, the hydrological data available is of short duration. Using more advanced methodologies it is possible to design the hydro-electric as well as irrigation schemes successfully. Reappraisal of the project will certainly indicate the change required in working system of the schemes. Polynomial curve for two variables (i.e. rainfall - runoff) is fitted by least Square method. Valunjkar [1] developed first-degree equation is found more consistent than the higher degree equations. The used equation is as below:

$$
y=-901.674+24.691 x
$$

where, $y=$ Monsoon runoff including $5 \%$ post-monsoon flow in $\mathrm{M} \mathrm{m}^{3}$ (million cubic metres) and $x=$ weighted monsoon rainfall in $\mathrm{cm}$ and correlation coefficient $=0.8853$. Annual runoffs for series of 80 years from 1914 to 1993 is considered in order to obtain 50,75, and $90 \%$ dependable yields after arranging annual runoffs in descending order. The values adopted at 50, 75, and $90 \%$ dependable yields are 2132,1655 , and $1413 \mathrm{M} \mathrm{m}^{3}$ respectively. 
The reservoir operation studies are made on the principles of conventional operation. The basic operation criterion with conventional method is expressed in terms of continuity equation. Using Data Base Management System (DBMS) operation and monitoring of reservoirs are carried out. The gross annual water resources available for irrigation use from Pench irrigation project at 50, 75 and $90 \%$ dependable yields (i.e. during excess, normal, and critical years of rainfall) are obtained as $1022.27,750.73$, and $578.32 \mathrm{M} \mathrm{m}^{3}$ respectively through simulation method.

\section{Mathematical model}

\subsection{Modified Linear Programming (MLP)}

The Modified linear programming (MLP) developed by Valunjkar and Bhave [2], related to optimization of cropping pattern could be given as:

$$
Z_{\max }=\sum_{j=1}^{J} N b_{j} \cdot A_{j}
$$

where, $\mathrm{j}=1,2 \ldots \mathrm{J} N b_{j}=$ net benefits in Rupees per hectare of the $\mathrm{j}^{\text {th }}$ crop, and $A_{j}=$ command area in hectare under $\mathrm{j}^{\text {th }}$ crop. The objective function is subject to the following factors.

(1) Availability of water resources and water requirement of Crops:

$$
\sum_{i=1}^{I}\left[A_{j}\left[\sum_{j=1}^{J} W_{i j}\right]\right] \leq \sum_{i=1}^{I} X_{i}
$$

where, $\mathrm{i}=1,2 \ldots \mathrm{I} ; W_{i j}=$ water requirement of $\mathrm{j}^{\text {th }}$ crop during $\mathrm{i}^{\text {th }}$ fortnight; and $\mathrm{X}_{\mathrm{i}}$ $=$ water available for irrigation during $\mathrm{j}^{\text {th }}$ fortnight.

(2) Land and crop area:

$$
\sum_{j=1}^{J} A_{j} \leq T_{A}
$$

where, $A_{j}=$ command area in hectare under $\mathrm{j}^{\text {th }}$ crop and $T_{A}=$ Total available irrigable command area.

(3) Soil and agricultural limits on crop area:

Upper limits

$$
A_{j} \leq C U_{j}
$$

Lower limits 


$$
A_{j} \geq C L_{j}
$$

where, $C U_{\mathrm{j}}=$ Maximum permissible $\mathrm{jth}$ crop cultivation area, $C L_{\mathrm{j}}=$ minimum area of the jth crop which is to be protected during critical period, and $A_{j}=$ area under existing or standing $\mathrm{j}^{\text {th }}$ crop during critical period. The numerical values of the parameters are considered as deterministic.

\subsection{Fuzzy Linear Programming (FLP)}

Fuzzy Linear Programming (FLP) developed by Valunjkar [3] corresponds to the linear programming problem formulated by Zimmermann [4] belongs to a certain class of decision problem analyzed in the form of satisfying decisions. This type of problems requires the aspiration level of the decision maker considering the objectives that are to be satisfied within the tolerable limits of the constraints. Hence, in FLP Wang [5] it is usually assumed that the aspiration levels concerning the objectives and constrains are not ordinary numbers but fuzzy numbers characterized by the membership function of the form:

$$
\mu_{z}(x)=\left[Z^{-}, Z, Z^{+}\right]
$$

where, $\mu_{z}(x)$ stands for membership functions of objectives based on prevailing price fluctuations of crops (i.e. net benefits from the crops); $Z^{-}=$ minimum limit of acceptance of benefit below which satisfaction level is zero and $Z^{+}=$maximum possible benefits from the crops that could be achieved.

$$
\mu_{w}(x)=\left[W^{-}, W, W^{+}\right]
$$

where, $\mu_{w}(x)$ stands for membership functions of fuzzy constraint coefficients based on number of watering required for each crop during kharif months/fortnights. $W^{-}$Stands for irrigation water requirement in kharif period during worst years and $W^{+}$denotes smallest possible requirement of irrigation water in kharif period during good years of rainfall.

$$
\mu_{x}(x)=\left[X^{-}, X, X^{+}\right]
$$

where, $\mu_{x}(x)$ stands for membership functions of fuzzy constraint resources based on availability of irrigation water needed; $X^{-}=$the minimum resources needed below which the satisfaction level is zero, and $X^{+}=$the maximum resources that could be used.

Thus the FLP formulated as: Maximize $\mathrm{Z}^{+}$subject to

$$
\mu_{w}(x)=\sum_{i=1}^{I} \sum_{j=1}^{J}\left[W^{-}, W, W^{+}\right] . A_{j} \leq \mu_{x}(x)=\sum_{i=1}^{I}\left[X^{-}, X, X^{+}\right]_{i}
$$


where, $\mu_{w}(x)=\left[W^{-}, W, W^{+}\right]$and $\quad \mu_{x}(x)=\left[X^{-}, X, X^{+}\right]$consist of triangular fuzzy numbers (assumed). Other constraints viz. total command area and agricultural limits based on soil fitness for cultivation are remains same. The total command area of Pench irrigation project is 104,476 $\mathrm{Ha}$ and agricultural limits (in $\mathrm{Ha}$ ) are also considered in the present study. FLP model involves maximization of benefits from 18 selected crops under sustainable condition subject to constraints of fortnightly irrigation water requirement by the crops and availability of fortnightly water resources from the reservoir. The results are compared with respect to conventional method of cropping pattern and net benefits accrued from the system.

\subsection{MATLAB Fuzzy Interface System (FIS)}

MATLAB Fuzzy Interface System (FIS) is a tool for formulating the mapping from a given input to an output using fuzzy logic toolbox. The mapping then provides a basis from which decisions can be made, or patterns discerned. Mamdani's fuzzy inference method is the most commonly seen fuzzy methodology. Mamdani's method was among the first control systems built using fuzzy set theory. Mamdani-type inference, as defined for the Fuzzy Logic Toolbox, expects the output membership functions to be fuzzy sets. FIS required by the more general Mamdani method, which finds the centroid of a twodimensional function. Rather than integrating across the two-dimensional function to find the centroid, the weighted average of a few data points can be used in the studies.

Information flows from left to right, from two or more inputs to a single output. The parallel nature of the rules is one of the more important aspects of fuzzy logic systems. Instead of sharp switching between modes based on breakpoints, will be glide smoothly from regions where the system's behaviour is dominated by either one rule or another. The FIS handles five parts of the fuzzy inference namely, FIS editor, Membership function editor, rule editor, rule viewer and surface viewer. The Fuzzy Logic Toolbox doesn't limit the number of inputs. However, the number of inputs may be limited by the available memory of the system. If the number of inputs is too large, or the number of membership functions is too big, then it may also be difficult to analyze the FIS using the other Graphical User Interface (GUI) tools. The Membership Function Editor is used to define the shapes of all the membership functions associated with each variable. The default, editor is of Mamdani-type inference. The Rule Editor is for editing the list of rules that defines the behaviour of the system. The FIS Editor displays general information about a fuzzy inference system.

In the present work of Bhoyar [6], $\mu_{w}(x)$ is membership functions of fuzzy constraint coefficients based on number of watering required for each crop during kharif months/fortnights and $\mu_{x}(x)$ is membership functions of fuzzy constraint resources based on availability of irrigation water needed are only considered and remaining parameters are unchanged. The sample membership functions are shown in Figure 1. 

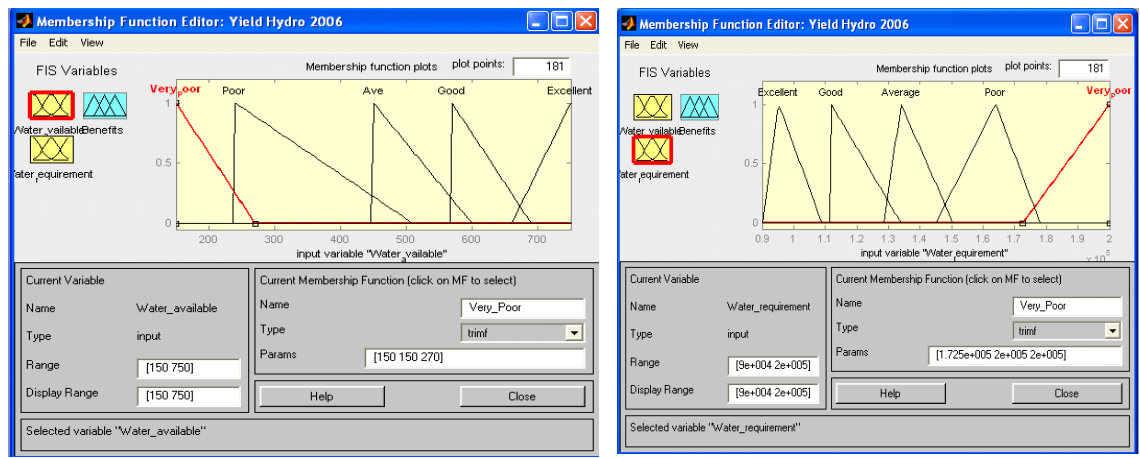

Figure 1: Membership functions of fuzzy constraints under extreme conditions of rainfall.


Figure 2: $\quad$ Rule Viewer of FIS during extreme conditions of rainfall.

Water requirement during kharif period and water availability under sustainable conditions i.e. normal to drought years of rainfall are considered based on weightage ranging from 1.0 to 0.10 . Accordingly, the rules are framed and results are obtained in terms of benefits from the yield of the crops. Figure 2 shows the rule viewer of FIS during extreme conditions of rainfall.

\section{Results}

A comparative analysis by optimization methods namely, MLP model, FLP model and through fuzzy interface system is carried out. In the FIS, the fuzziness in the water requirement by the crops and availability of surface water resources has been incorporated. Data used in the present work is related to $75 \%$ dependable yield is considered as normal year of rain fall and weightage is given as 1.0 in fuzzy logic system. Similarly, water requirement by the 18 crops during normal year to drought years of rainfall is considered in the analysis. The comparative results obtained from MLP, FLP and FIS of four prominent cases only are shown in Table 1. 
Table 1: $\quad$ Area covered by different crops under sustainable conditions using MLP, FLP and FIS model.

\begin{tabular}{|l|l|l|l|l|c|c|}
\hline Models $\rightarrow$ & MLP & FLP & FIS & MLP & FLP & FIS \\
\hline Weightage $\rightarrow$ & 75 & {$[1,1,1]$} & {$[1,1,1]$} & 90 & {$[1,0.1,0.1]$} & {$[0.1,0.1,0.1]$} \\
\hline Crops & & & & & & \\
\hline Sugarcane (P) & -- & - & -- & -- & - & - \\
\hline Paddy (K) & -- & - & -- & -- & - & - \\
\hline Soyabean (K) & 6378 & 6378 & 6378 & -- & 6378 & 6378. \\
\hline Wheat (R) & 5181 & 5181 & 2834 & 721 & - & - \\
\hline Gram (R) & -- & - & 1626 & 1626 & - & - \\
\hline Maize (K) & -- & - & -- & -- & - & - \\
\hline G'Nut (K) & -- & - & -- & -- & - & - \\
\hline Cotton (8 M) & 26402 & 26402 & 46485 & 7856 & 2613 & 6165. \\
\hline Chillies (R) & -- & - & -- & -- & - & - \\
\hline $\begin{array}{l}\text { Veg./Potato } \\
\text { Kharif, Rabi) }\end{array}$ & 9351 & 9351 & 9351 & 9351 & 9351 & 9351 \\
\hline Oilseeds (R) & 5632 & 5631 & 12784 & 12785 & - & 7186 \\
\hline Pulses (K) & 13437 & 1343 & 13437 & 2617 & 13437 & 13436. \\
\hline $\begin{array}{l}\text { Other Kharif } \\
\text { grains }\end{array}$ & -- & - & -- & -- & - & - \\
\hline Soyabean (R & 6378 & 6378 & 6378 & 6378 & - & - \\
\hline Maize (R) & -- & - & -- & -- & - & - \\
\hline G'Nut (HW) & 1365 & 1365 & & 1365 & - & - \\
\hline Chillies (HW) & 5571 & 5571 & 5571 & 5571 & 5571 & 5571 \\
\hline $\begin{array}{l}\text { Vegetables } \\
\text { (Hot Weather) }\end{array}$ & 9351 & 9351 & 9351 & 9351 & 9351 & 9351 \\
\hline $\begin{array}{l}\text { Area irrigated in } \\
\text { Ha. }\end{array}$ & 89406 & 89046 & 111205 & 57622 & 42,615 & $57,328)$ \\
\hline $\begin{array}{l}\text { Total benefits (in } \\
\text { Rs. Million) }\end{array}$ & 530.86 & 531.13 & 655.13 & 332.40 & 326.50 & 389.60 \\
\hline
\end{tabular}

It can be seen from the Table 1 that, maximum benefits obtained under normal year of rainfall through MLP, FLP, FIS are Rs.530.86, 531.13 and 655.13 million respectively, and benefits obtained during critical rainfall year are Rs. $332.40,326.50$ and 389.60 million respectively. There is no change in area under Vegetables (2S), Soybean (kharif) and Chillies (hot weather) at all the conditions. Variations in oilseeds are found in the cases of FLP and FIS. Results obtained from FLP and FIS found more suitable compared with MLP especially under sustainable conditions. Figure 3 shows the comparative benefits obtained from MLP, FLP and FIS models.

\section{Conclusions}

The FLP and FIS are constructed with fuzziness involved in constraint coefficients and available resources of surface water in order to work out benefits 
from the crops under sustainable situation. Optimal results derived from FLP and FIS are compared with MLP. The result shows that there is no variation when the water is utilized in rabi season. Similarly, marginal variations in benefits are observed during normal years of rainfall. The implementation of modified linear programming in actual field may not be found viable due to its deterministic approach. On the other hand models having probabilistic approach namely, FLP and FIS could be used for revising the cropping pattern under sustainable conditions.

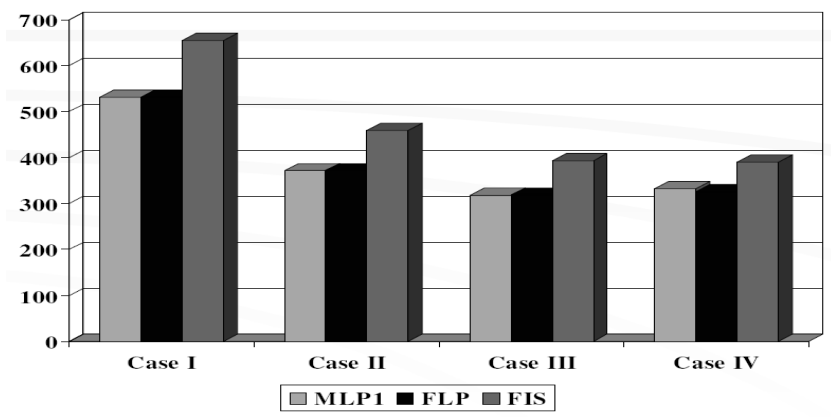

Figure 3: Results showing benefits from cropping pattern in Rs. Million under sustainable conditions.

\subsection{Contributions}

- Fuzzy logic approach under sustainable conditions is used for better cropping pattern.

- Fuzzy logic approach is a probabilistic and it is preferred over deterministic approach.

- In the present work all the methods based on scientific techniques of optimization hence these methods are superior to conventional practices of cropping pattern.

\section{References}

[1] Valunjkar S.S., Water planning and yield studies for Pench river project complex. Proceedings of All India Seminar on Hydraulic Engineering, Institution of Engineers (India), Nagpur Local Centre, India, pp.128 $132,1996$.

[2] Valunjkar S.S. and Bhave P.R., Optimization of available water resources for irrigation use-case study: Pench river project complex, Second International $R \& D$ conference, Publications: Central Board of Irrigation \& Power (Publication Unit), New Delhi, India, Water Resources, Vol. I., pp.128-296, 1997.

[3] Valunjkar S.S., Development of fuzzy logic system for optimal water resources and cropping planning in context with sustainable development, 
R\&D Project Report (Unpublished), Submitted to the All India Council for Technical Education, New Delhi, India, 2005.

[4] Zimmermann H.J., Fuzzy set theory and its applications (second edition, chapter 12). Topic in Decisions Making in Fuzzy Environments, Kluwer Academic Publications, New Delhi, India, pp. 241-282, 1996.

[5] Wang Li-Xin, A course in fuzzy systems and control (chapter 30). Topic in Fuzzy Linear Programming, Prentice-Hall International, Inc, New Delhi, India, pp. 381-392, 1997.

[6] Bhoyar P. N. "Planning and Optimization of Cropping Pattern: "A Case Study of Pench Irrigation Project, Maharashtra State, India”, M.E. (CivilWater Resources Engineering) Dissertation Report (Unpublished), Department of Civil Engineering, Government College of Engineering, Aurangabad, Maharashtra State, India, 2005. 